\title{
Research on Characteristics of Soft Switching Bidirectional Converter Based on Electric Vehicle
}

\author{
Baowen Sun \\ Department of Automotive Engineering of Guangdong Vocational College of science and technology, \\ Zhuhai, Guangdong, China, 519090
}

Email: 623320801@qq.com

\begin{abstract}
A practical soft switch bidirectional converter for EV is presented, which can realize the bidirectional flow of energy between the energy storage battery and the motor of the EV. By choosing an appropriate resonant circuit, the soft switch characteristics of the converter in Buck mode and boost mode are analyzed, and a prototype is made. The waveform of the power tube switch state is collected by an oscilloscope, which improves the energy conversion efficiency of the converter and verifies the rationality of the design.
\end{abstract}

Keywords: Electric vehicle, Soft switch, Bidirectional converter, Mode

\section{INTRODUCTION}

With the increasingly prominent environmental and energy issues, the development of electric vehicles is particularly important ${ }^{[2]}$.Electric vehicle can work in both electric and feedback braking state when working. The stability of voltage and charging using braking energy cannot be separated from the help of bidirectional DC/DC converter ${ }^{[1]}$. However, there are still many problems in the bi-directional converter currently used. For example, in the process of power transmission, because the switch tube of the bi-directional converter works in hard switch state, there is a large switch loss. Some bidirectional converters are complex in structure and unstable in operation, and others have problems such as spontaneous combustion due to unreasonable design. For this reason, the soft switch converter with high energy efficiency and simple structure has become a technology that must be tackled in the development of electric vehicle. Based on this, a soft switch bi-directional converter for electric vehicle is designed, which improves the efficiency of the converter and has a simple structure, showing good performance.

\section{CIRCUIT TOPOLOGY AND WORKING PRINCIPLE}

Soft-switch two-way converter connects the motor and battery of the electric vehicle separately and acts as an interface for energy exchange between them. The circuit topology of the soft-switch bidirectional converter is shown in Figure $1 . V_{\text {in }}$ is the DC voltage of the motor, $V_{o}$ is the battery voltage, $S_{1}$ and $S_{3}$ are the main switches of the soft-switching bidirectional converter, $S_{2}$ and $S_{4}$ are the auxiliary switches of the soft-switching bidirectional converter, $\mathrm{D}_{1}$ and $\mathrm{D}_{4}$ are the reverse parallel diodes of the switch tube, $\mathrm{L}$ is the main inductance, $\mathrm{L}_{\mathrm{r} 1}$ and $\mathrm{L}_{\mathrm{r} 2}$ are the resonant inductance, $\mathrm{C}_{\mathrm{r}}$ is the resonant capacitor, which work together to realize the soft-switching function of the bidirectional converter. 


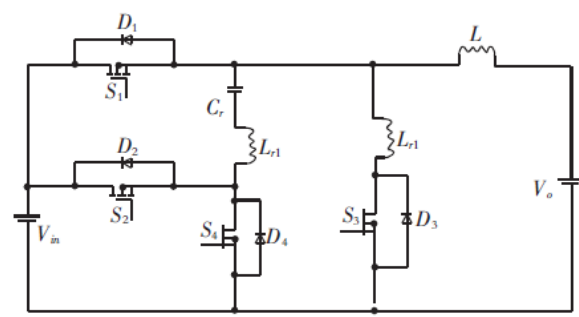

Figure1 Soft switching bidirectional converter circuit topology

The soft-switch bidirectional converter consists of two working modes, buck mode and boost mode ${ }^{[3]}$. When the motor brakes in reverse, the motor charges to the battery through a soft-switch bidirectional converter, which operates in Buck mode. When the motor drives the electric vehicle normally, the battery supplies power to the motor through a soft-switch bidirectional converter, which works in boost mode. Due to the existence of resonant inductance and capacitance, the switch in soft-switching bidirectional converter always works in zero-current state, that is, soft-switching state.

When the soft switch bi-directional converter is in Buck mode, the switch $S_{1}$ and $S_{2}$ are in working state, and $S_{3}$ and $S_{4}$ are always in off state. The buck mode of the converter can be divided into four stages.

Stage $1\left(\mathrm{t}_{0}<\mathrm{T}<\mathrm{t}_{1}\right)$ : When buck mode starts $\mathrm{t}=$ $t_{0}$, switches $S_{1}$ and $S_{2}$ are turned off, and the output current is stored by inductance and supplied to the battery port through the inverse shunt diode $\mathrm{D}_{3}$ of switch $\mathrm{S}_{3}$.

Stage $2\left(t_{1}<T<T_{2}\right)$ : When $t=t_{1}$, switch $S_{1}$ is on and $S_{2}$ is off. The capacitance $C_{r}$ resonates with the inductance $L_{r 1}$, forcing the current in diode $D_{3}$ to gradually decrease to zero, creating a zero-current switch condition for switch $S_{1}$, the soft-switch condition. The current expressions of the voltage at both ends of the resonant capacitor $\mathrm{C}_{\mathrm{r}}$ and the resonant inductance $\mathrm{L}_{\mathrm{r} 1}$ are:

$$
\begin{aligned}
& V_{C r}(t)=-V_{C r \max } \cos \left(\omega_{0}\left(t-t_{1}\right)\right) \\
& I_{L r 1}(t)=I_{L}+\frac{V_{C r \max }}{Z_{0}} \sin \left(\omega_{0}\left(t-t_{1}\right)\right)
\end{aligned}
$$

Among

$$
\begin{aligned}
& Z_{0}=\sqrt{L_{r 1} / C_{r}} \\
& \omega_{0}=1 / \sqrt{L_{r 1} C_{r}}
\end{aligned}
$$

In the formula: $\mathrm{V}_{\mathrm{Cr}}$ is the voltage at both ends of capacitor $\mathrm{C}_{\mathrm{r}}, \mathrm{I}_{\mathrm{Lr} 1}$ is the current of inductance $\mathrm{L}_{\mathrm{r} 1}$, $\mathrm{V}_{\mathrm{Crmax}}$ is the peak voltage at both ends of capacitor $C_{r}, I_{L}$ is the current of inductance $L, L_{r 1}$ is the inductance value of inductance $\mathrm{L}_{\mathrm{r} l}$, and $\mathrm{C}_{\mathrm{r}}$ is the capacitance value of capacitor $\mathrm{C}_{\mathrm{r}}$.

Stage $3\left(\mathrm{t}_{2}<\mathrm{T}<\mathrm{t}_{3}\right)$ : When $\mathrm{t}=\mathrm{t}_{2}$, capacitance $\mathrm{C}_{\mathrm{r}}$ and inductance $L_{r 1}$ stop resonance, switch $S_{1}$ is on, the converter is in Buck operation, and the motor supplies power to the battery through the converter.

Stage $4\left(T_{3} \leqslant T<T_{4}\right)$ : when $t=T_{3}$, the switch $\mathrm{S}_{2}$ is turned on, the capacitor $\mathrm{C}_{\mathrm{r}}$ and the inductor $\mathrm{L}_{\mathrm{r} 1}$ begin to resonate, and the voltage at both ends of the capacitor $C_{r}$ reaches the peak after half a cycle. The resonance between capacitor $C_{r}$ and inductor $\mathrm{L}_{\mathrm{r} 1}$ forces the current in switch $\mathrm{S}_{1}$ to zero gradually, which creates zero current switching condition for switch $S_{1}$, that is soft switching condition. In this stage, the expressions of the voltage at both ends of the resonant capacitor $C_{r}$ and the current of the resonant inductor $\mathrm{L}_{\mathrm{r} 1}$ are as follows:

$$
\begin{aligned}
& V_{C r}(t)=V_{C r \max } \cos \left(\omega_{0}\left(t-t_{3}\right)\right) \\
& I_{L r 1}(t)=\frac{V_{C r \max }}{Z_{0}} \sin \left(\omega_{3}\left(t-t_{3}\right)\right)
\end{aligned}
$$

When the soft-switch bidirectional converter is in boost mode, the switches $S_{3}$ and $S_{4}$ are in working state, and $S_{1}$ and $S_{2}$ are always in off state. The boost mode of the converter can be divided into six stages.

Stage $1\left(t_{0}<T<T_{1}\right)$ : When $t=t_{0}$, the current of the main inductance $L_{1}$ flows through the inductance $\mathrm{L}_{\mathrm{r} 2}$ and the switch $\mathrm{S}_{3}$, the inductance $\mathrm{L}_{\mathrm{r} 2}$ is in the energy storage state, and the switch $\mathrm{S}_{3}$ zero current is on.

Stage $2\left(\mathrm{t}_{1}<\mathrm{T}<\mathrm{t}_{2}\right)$ : When boost mode starts, $\mathrm{t}=$ $t_{1}$, and the current in inductance $L_{r 2}$ reaches its peak. Inductance $\mathrm{L}_{\mathrm{r} 1}$, inductance $\mathrm{L}_{\mathrm{r} 2}$ and 
capacitance $\mathrm{C}_{\mathrm{r}}$ produce resonance. The current expressions for the voltage at both ends of the capacitor $\mathrm{Cr}$ and the inductance $\mathrm{L}_{\mathrm{r} 2}$ are:

$V_{C r}(t)=V_{C r \max } \cos \left(\omega_{0}\left(t-t_{1}\right)\right)$

$I_{L r 2}(t)=I_{L}+\frac{V_{C r \max }}{Z_{0}} \sin \left(\omega_{0}\left(t-t_{1}\right)\right)$

Among

$Z_{0}=\sqrt{\left(L_{r 1}+L_{r 2}\right) / C_{r}}$

$\omega_{0}=1 / \sqrt{\left(L_{r 1}+L_{r 2}\right) / C_{r}}$

Stage $3\left(t_{2}<\mathrm{T}<\mathrm{T}_{3}\right)$ : When $\mathrm{t}=\mathrm{t}_{2}$, the circuit of the capacitor $\mathrm{C}_{\mathrm{r}}$ becomes zero and the resonance in the converter stops. The main inductance $\mathrm{L}$ is in the state of energy storage.

Stage $4\left(t_{3}<T<t_{4}\right)$ : When $t=t_{3}$, the switch $S_{4}$ is on, the inductance $\mathrm{L}_{\mathrm{r} 1}, \mathrm{~L}_{\mathrm{r} 2}$ and capacitance $\mathrm{C}_{\mathrm{r}}$ are always in resonance state, and when $\mathrm{t}=\mathrm{t}_{4}$, the current in inductance $\mathrm{L}_{\mathrm{r} 1}$ is zero.

Stage $5\left(t_{4}<T<t_{5}\right)$ : When $t=t_{4}$, the resonance in the converter stops, the main inductance current $\mathrm{I}_{\mathrm{L}}$ charges the capacitor $\mathrm{C}_{\mathrm{r}}$, and the voltage at both ends of the capacitor $\mathrm{C}_{\mathrm{r}}$ increases linearly. When $\mathrm{t}=\mathrm{t}_{5}$, the voltage at both ends of the capacitor $C_{r}$ reaches the battery voltage $V_{o}$. The expression of the voltage at both ends of the capacitor $\mathrm{C}_{\mathrm{r}}$ at this stage is:

$V_{C r}(t)=V_{C r}\left(t_{4}\right) \frac{I_{L}}{C_{r}}\left(t-t_{4}\right)$

Stage $6\left(\mathrm{t}_{5}<\mathrm{T}<\mathrm{t}_{6}\right)$ : When the voltage at both ends of the capacitor $\mathrm{C}_{\mathrm{r}}$ reaches the $\mathrm{DC}$ voltage of the motor $V_{\text {in }}$, the diode $D_{1}$ is turned on under soft switch condition, and the converter is in the state of energy output. When $t=t_{6}$, the switch $S_{3}$ is switched on again to start the next working cycle.

\section{EXPERIMENTAL RESULTS AND} ANALYSIS

Based on the soft-switch bi-directional converter structure proposed above, a prototype with power of $1 \mathrm{~kW}$ has been made. The prototype's motor DC voltage $V_{\text {in }}=400 \mathrm{~V}$, battery voltage $V_{o}=$ $400 \mathrm{~V}$, operating frequency $\mathrm{f}=100 \mathrm{kHz}$. The inductance values of $\mathrm{L}_{\mathrm{r} 1}$ are $\mathrm{L}_{\mathrm{r} 1}=10 \mu \mathrm{H}, \mathrm{L}_{\mathrm{r} 2}=1$ $\mu \mathrm{H}$, and $\mathrm{C}_{\mathrm{r}}=10 \mathrm{nF}$. For experimental observation, the voltage waveform amplitude is reduced to $1 / 100$ when the sample is measured. For current waveform measurement, the corresponding current probe is used and the current waveform amplitude is reduced to $1 / 10$ ${ }^{[4]}$.The experimental circuit waveforms are shown in Figure2, Figure3, Figure4 and Figure 5.

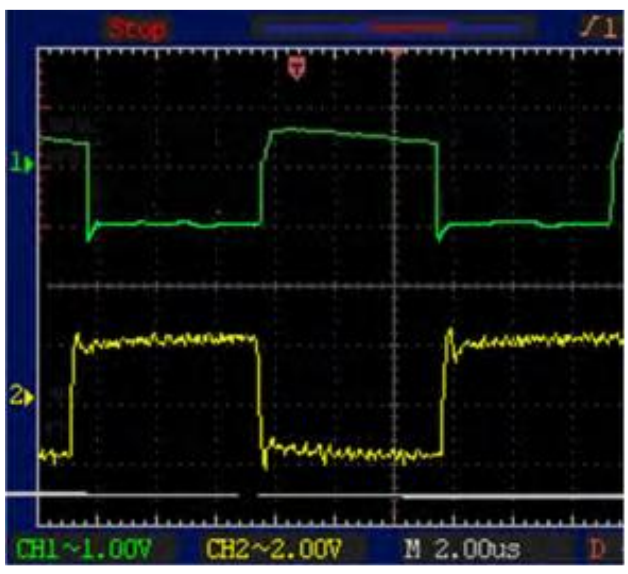

Figure 2 Voltage waveform and current waveform of switch $\mathrm{S}_{1}$



Figure3 Voltage waveform and current waveform of switch $\mathrm{S}_{2}$

The voltage and current waveforms of the main switches $S_{1}$ and $S_{3}$ of the soft switch bidirectional converter are shown in Figure2 and Figure4.As shown in the diagram, the switches $S_{1}$ and $S_{3}$ have achieved zero current shut-off, and the switches operate in the Zero Current Switch (ZCS) state completely during the shut-off process. The voltage and current waveforms of the auxiliary switches $\mathrm{S}_{2}$ and $\mathrm{S}_{4}$ of the soft switch 
bidirectional converter are shown in Figure 3 and Figure5. The diagram shows that the switch also works in the zero current switch state.

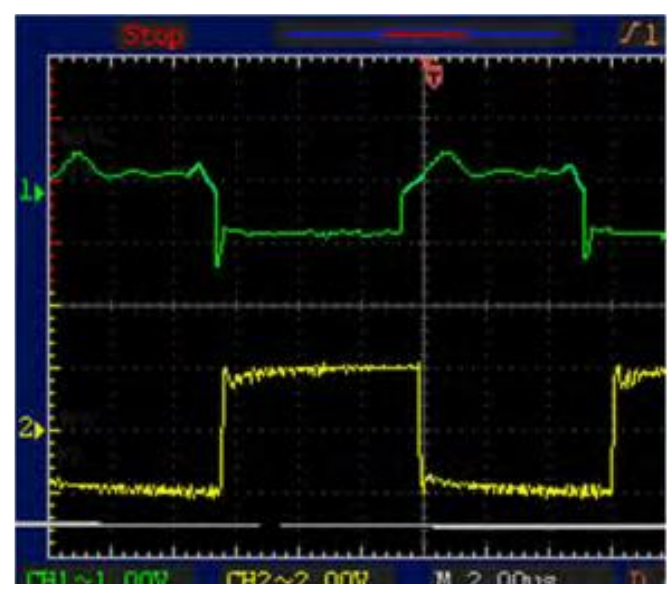

Figure4 Voltage waveform and current waveform of switch $\mathrm{S}_{3}$

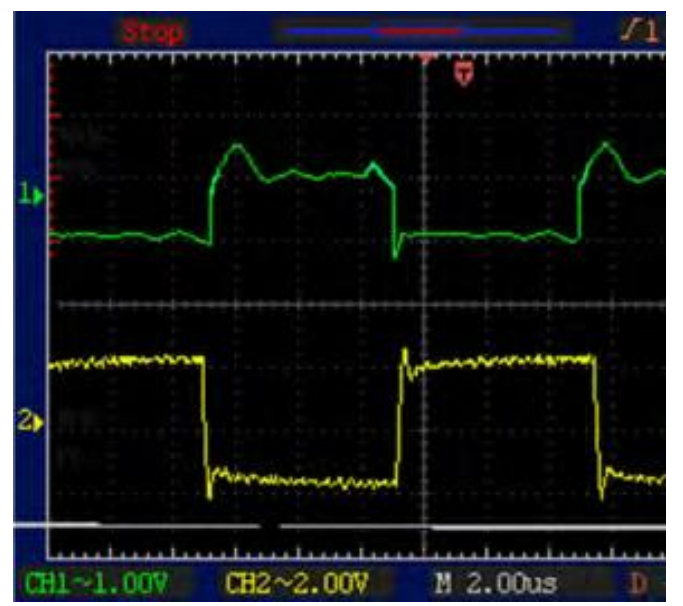

Figure5 Voltage waveform and current waveform of switch $\mathrm{S}_{4}$

\section{Conclusion}

The soft switch bi-directional converter of the electric vehicle can be used as the interface between the energy storage battery of the electric vehicle and the energy exchange of the motor. When the electric vehicle is running normally, the converter is in boost mode, and the energy flows from the energy storage battery to the motor. When the electric vehicle is in braking state, the converter is in Buck mode, and the energy flows from the motor to the energy storage battery. The converter has designed a related resonant circuit, so that the switches in the converter can achieve soft switch, which greatly improves the efficiency of the converter ${ }^{[5]}$.

\section{ACKNOWLEDGMENT}

This research was financially supported by the characteristic innovation project fund of Guangdong Provincial Department of education (2018GKTSCX027).

\section{REFERENCES}

[1] Sha Guanglin, Wang Cong, Cheng Hong, etc. Soft switch implementation and hardware parameter optimization of bidirectional full-bridge DC converter $[\mathrm{J}]$. Electrical applications, 2015 (12): 31-34.

[2] Li Hongzhu, Ma Wentao. Research on Interleaved Parallel Magnetically Integrated Soft-Switched Bidirectional DC/DC Converter [J]. Power Electronics Technology, 2015 (7): 12-15.

[3] Huang Bin, Wang Yue, Gaoyuan. Soft switch characteristics of isolated two-way full-bridge DC converter applied to energy storage system [J]. Electrical Drive, 2014 (11): 23-27.

[4] Xu Xianghua, Zhang Jiasheng, Hao Xiujie. A new phase-shifted full-bridge soft switch converter [J]. Electrical Drive, 2014,44(8): 27-30.

[5] Successful, Chen Tefang, Yu Mingyang. A new active secondary clamp full bridge zero voltage zero current soft switch PWM converter $[\mathrm{J}]$. China Journal of Electrical Engineering, 2008,28(12): 44-49.

[6] Electric vehicle DC/DC converter (GB/T 24347-2009)

[7] Camara M B,Gualous H,Gustin F.DC/DC converterdesign for super capacitor and battery power managementin hybrid vehicle 
applications - polynomial controlstrategy.

IEEE Transactions on Industrial

Electronics, 2010.

[8] Amjadi, Z, Williamson, S.S. Digital Control of a Bidirectional DC/DC Switched Capacitor Converter for Hybrid Electric Vehicle Energy Storage System Applications[J]. IEEE Transactions on Smart Grid, 2014, 5(1): 158-166.

[9] J. He, X. Liu,et al. High Annealing Stability of InAlZnO Nanofiber Field-Effect Transistors with Improved Morphology by $\mathrm{Al}$ Doping. Journal of Physical Chemistry Letters, 12.4(2021)1339-1345.

[10] H. Zu, Y. Chang, H. Li, et. al., Modulating the Transport Properties of Metal Oxide Nanofibers Transistors by Controlling the Grain Size. IEEE Electron Device Letters. 42.6(2021)855-858.

[11] D. Liu, B. Yu, M. Liao, et. al.,Self-Powered and Broadband Lead-Free Inorganic Perovskite Photodetector with High Stability, ACS Applied Materials \& Interfaces, 12.27(2020) 30530 -30537.

[12] P. Xu, J. Cao, et. al., Quantum chemical study on the adsorption of megazol drug on the pristine BC3 nanosheet, Supramolecular Chemistry, 33(2021)63-69. 